\title{
A Method to Predict Banana Pseudostem's Strength at Seedling Stage
}

\author{
Shenghe Chang1,2*, Zhengjing $\mathrm{Wu}^{3^{*}}$, Wei Sun ${ }^{1,2}$, Lan Qiao ${ }^{3}$, Qi Zeng33, Jingyi Zhang3, Haiyan Shu ${ }^{1,2 \#}$ \\ ${ }^{1}$ Haikou Experimental Station, Chinese Academy of Tropical Agricultural Sciences, Haikou, China \\ ${ }^{2}$ The Key Laboratory of Hainan Banana Genetics and Breeding, Haikou, China \\ ${ }^{3}$ School of Forestry, Henan University of Science and Technology, Luoyang, China \\ Email: "shuhy@zzu.edu.cn
}

How to cite this paper: Chang, S.H., Wu, Z.J., Sun, W., Qiao, L., Zeng, Q., Zhang, J.Y. and Shu, H.Y. (2018) A Method to Predict Banana Pseudostem's Strength at Seedling Stage. Advances in Bioscience and Biotechnology, 9, 391-396.

https://doi.org/10.4236/abb.2018.99027

Received: July 24, 2018

Accepted: August 26, 2018

Published: August 29, 2018

Copyright (c) 2018 by authors and Scientific Research Publishing Inc. This work is licensed under the Creative Commons Attribution International License (CC BY 4.0).

http://creativecommons.org/licenses/by/4.0/

\begin{abstract}
Banana industry played important roles in Chinese economics. Banana production was always affected heavily by typhoon. Selecting new cultivars with high strength was the basic way to resolve this problem. If the selecting work was performed at mature stage, it will need large area and much labor. If this work can be done at seedling stage, this process will be simplified significantly. We found that banana plants that had high strength at seedling stage always had high strength at mature stage. The physical strength of seedling pseudostem was closely related with pseudostem diameter, lignin content and the expression of 4-coumarate:CoA ligase gene Mu4CL15. Those seedlings whose pseudostem had bigger diameter, more lignin content and higher expression of Mu4CL15 always had higher strength to resist lodging. Through screening plants whose pseudostem had bigger diameter, more lignin content and higher expression of Mu4CL15, plants with high-strength pseudostem can be selected. Using this method, thousands of seedlings can be identified in short time. This process does not need large area and much labor. If this method was applied, the process of breeding new cultivars of banana with high resistance to lodging will be accelerated.
\end{abstract}

\section{Keywords}

Banana, Lodging, Identifying, Seedling Stage

\section{Introduction}

Banana is a tropical fruit with large production in China [1]. Banana industry played important roles in Chinese economics. The main-production areas of 
banana in China included Guangdong, Hainan, Yunan, Guangxi, Fujian, Taiwan. These provinces located in subtropical monsoon area, which are always affected by typhoon [2]. When typhoon blows, the leaves of banana plants are always divided. Sometimes, the whole plant lodged and no fruit can be got. Culturing lodging-resistant varieties is the basic way to resolve this problem. Screening and identifying the germ plasm resource collected was the first step to breed a new variety. The plant of banana is large. A single banana plant required a large area to grow. On average, an acre space can only accommodate 780 to 1080 banana plants [3]. Identifying a new variety always need to screen thousands of plants. If the screening work was performed at mature stage, this will need large area and nearly is impossible. If the pseudostem strength of banana can be identified in seedling stage, this problem will be resolved. In this research, a method was constructed to predict the pseudostem strength of banana at seedling stage. Thousands of banana plants can be screened and identified in short time. This method did not require large area or much labor. The lodging-resistant breeding process will be shorted significantly if this method was used.

\section{Methods and Results}

The detailed method was as the following.

1) A sucker was fetched from the mother plant of a banana germ.

2) The sucker was kept in a plastic bag. The humidity in the plastic bag was $75 \%$.

3) The sucker was transferred to lab. In lab, the outer skin of the sucker was removed. The rest of the sucker was soaked in washing-powder solution for five minutes. And then, the solution was discarded. The sucker was washed with distilled water three times. Five minutes for each time.

4) The sucker was sprayed with $70 \%$ of ethanol for three times. And then, the sucker was washed with sterilized water three times. The sucker was soaked in $0.1 \%$ mercuric chloride for 5 minutes. The sucker was washed with sterilized water for three times.

5) In a super clean bench, the outer layer of the sucker was removed until the diameter of the sucker was about two centimeters.

6) The sucker was divided into four parts in a Petri dish. The divided parts were cultured on M1 solid medium. The formulation of M1 was MS + 6-BA 5.0 + NAA 0.2, pH5.8. The culturing bottles were put in dark, $28^{\circ} \mathrm{C}$.

7) After 30 days, the seedlings were transferred onto M2 solid medium. The formulation of M2 was MS + NAA0.2, pH5.8. The culturing bottles were put in $28^{\circ} \mathrm{C}$, the photoperiod was 12 hours light/12 hours dark. The light intensity was 2500 lux.

8) After 18 days, the bottles were transferred into a greenhouse in which the light intensity was the same as the outer environment. The lid of the bottle was loosed and the outer wind can enter.

9) After one week, the seedlings with the bottle were transferred into a cultur- 
ing greenhouse. The seedlings were fetched from the bottle. The solid medium on the roots were washed with tap water. After the solid medium was removed completely, the seedling was cultured in a culture pot. The substrate in the pot was the mixture of gardening soil and coconut husk (1:1). The substrate was watered with nutrient solution. The formulation of the nutrient solution was as the following. Ammonium nitrate $0.2 \mathrm{~g}$, calcium superphosphate $0.6 \mathrm{~g}$, potassium nitrate $0.55 \mathrm{~g}$, magnesium sulfate $0.54 \mathrm{~g}$, calcium sulfate $0.08 \mathrm{~g}$, ferrous sulfate $0.003 \mathrm{~g}$, manganese sulfate $0.002 \mathrm{~g}$, boric acid $0.003 \mathrm{~g}$, zinc sulfate $0.002 \mathrm{~g}$, ammonium molybdate $0.002 \mathrm{~g}$, dissolved in $2 \mathrm{~kg}$ of water.

10) The seedlings were watered one time every day.

11) When the fifth leaf appeared, the diameter of the pesudostem of the seedling was measured with a vernier caliper.

12) A part of the out layer of the seedling pseudostem was fetched (Figure 1). The total RNA was extracted. The first-strand cDNA samples were syntheized using total RNA. RQRT-PCR was done for Mu4CL15 using the specific primers P1 (5'-ATGGAGTCATACTCGATGCCGGAG-3') and P2 (5'-

TCAAGCGGATGGAAACTGGCTTC-3') according to the published genomic sequence of banana (GSMUA_Achr4P05820_001). PCR reaction was carried out for 30 cycles $\left(94^{\circ} \mathrm{C} 30 \mathrm{~s}, 63^{\circ} \mathrm{C} 60 \mathrm{~s}, 72^{\circ} \mathrm{C} 90 \mathrm{~s}\right)$. As a control, RT-PCR was performed using two primers (P5: 5'-CCTGCTCTCTACATTTACAT-3' and P6: 5'-CCTTCATCGCCTTCATCACC-3') specific for the wheat tublin gene Mutubulin. PCR was performed for 30 cycles $\left(94^{\circ} \mathrm{C} 30 \mathrm{~s}, 50^{\circ} \mathrm{C} 60 \mathrm{~s}, 72^{\circ} \mathrm{C} 120 \mathrm{~s}\right)$. PCR results were analyzed using $1.0 \%$ agarose gel electrophoresis (Figure 2). For every reaction, four repetitions were performed.

13) A part of the out layer of the seedling pseudostem was fetched. The samples were freeze-dried and then, they were ground into fine powder using liquid nitrogen. Samples were put in Soxhelt's and treated with ethanol for 24 hours.

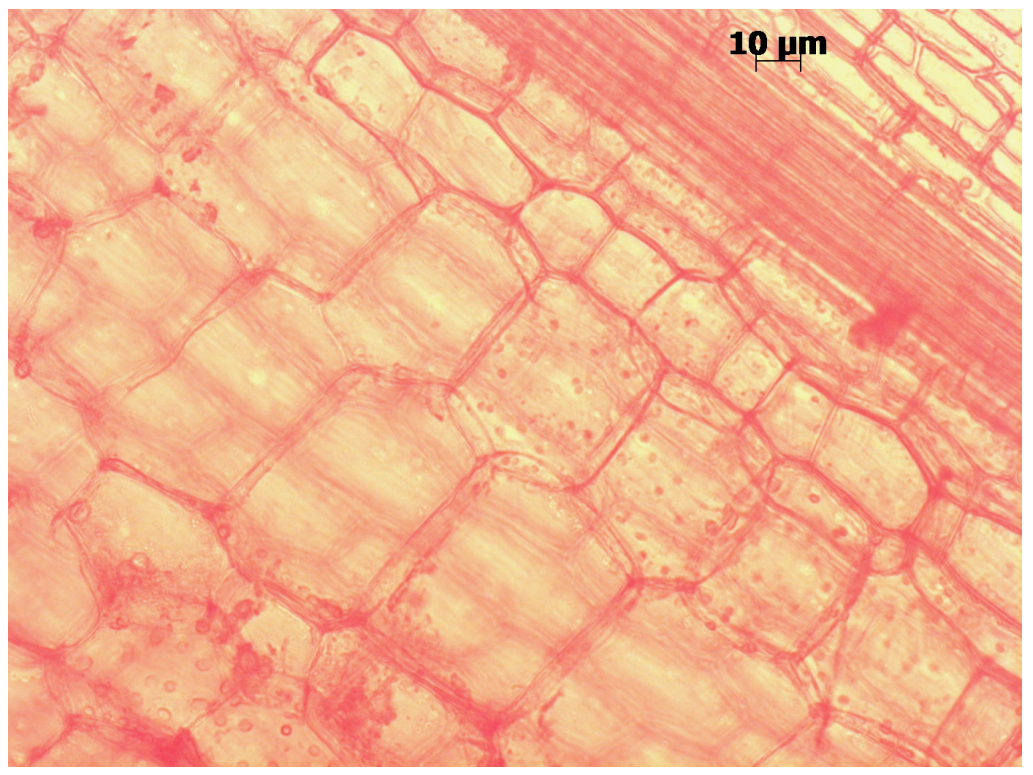

Figure 1. A part of the out layer of the seedling pseudostem fetched. 


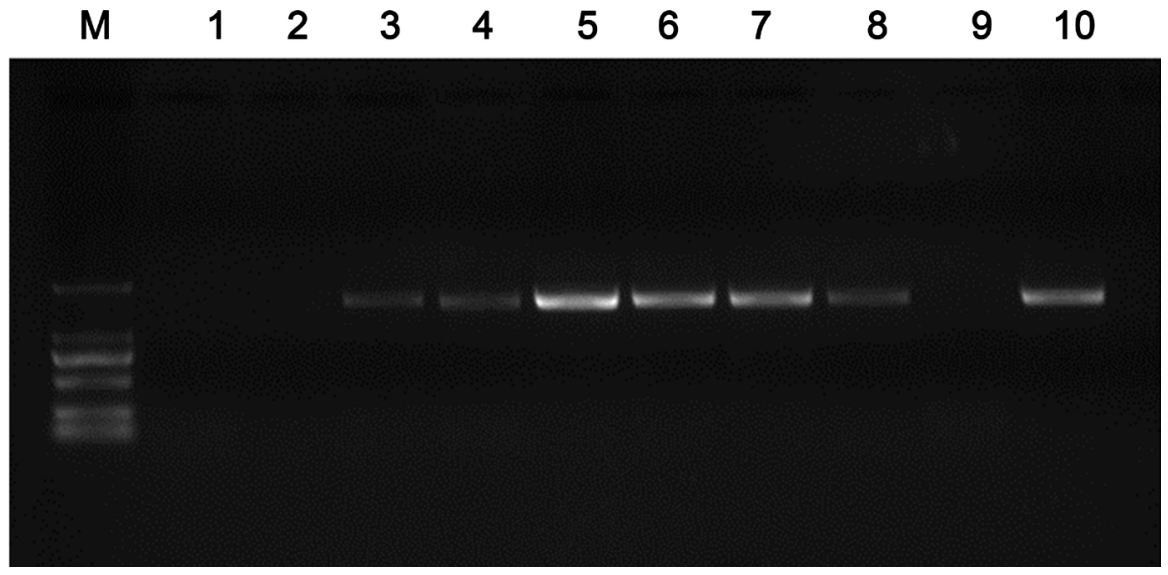

Figure 2. PCR results for Mu4CL15 using genomic DNA from different lines as templates. M was DNA marker (D2000) (Tiangen Biotech, Beijing, China). 1 - 10 represented different banana strains.

After the powder was air-dried, it was put in test tube. Three $\mathrm{ml}$ of $72 \%$ sulphuric acid was added and vortexed for one minute. The tubes were put in $30^{\circ} \mathrm{C}$ water bath for one hour, votex every five minutes. Eighty-four $\mathrm{ml}$ of distilled water was added and the sulphuric acid was adijusted to $4 \%$. The test tubes were put in $121^{\circ} \mathrm{C}$ for 1 hour and then, the mixture was filtered using filter paper. The filtrate was collected and A320 nm was measured, using $4 \%$ sulphuric acid as control. ASL $(\%)=\mathrm{A} 320 \mathrm{~nm} \times 86.73 \times \mathrm{n} /(30 \times \mathrm{W}) \times 100 \%$. $\mathrm{N}$ was the dilution factor. $\mathrm{W}$ was the dry weight of the sample. Thirty represented the extinction coefficient. Pot was kept in $575^{\circ} \mathrm{C} \pm 25^{\circ} \mathrm{C}$ in muffle furnace for 6 hours. The sample was cooled to room temperature and weighed. The value was named as $\mathrm{W} 1$. The filter paper was dried in $105^{\circ} \mathrm{C}$ for 6 hours. And then, it was cooled to room temperature and weighed. The value was named as W2. A single filter paper was dried in $105^{\circ} \mathrm{C}$ for 6 hours. It was cooled to room temperature and weighed. The value was named as $\mathrm{W} 3.50 \mathrm{ml}$ of distilled water was used to wash the residue. Filter paper and residue were both put in pot and dried in $105^{\circ} \mathrm{C}$ for 4 hours. They were cooled and weighed. The value was named as W4. And then, the pot containing filter paper and residue was put in muffle furnace in $575^{\circ} \mathrm{C} \pm 25^{\circ} \mathrm{C}$ for 24 hours. They were cooled to room temperature and weighed. The value was named as W5. AIL $=(\mathrm{W} 4-\mathrm{W} 5-\mathrm{W} 3 \times \mathrm{W} 2 / \mathrm{W} 1) / \mathrm{W} \times 100 \%$. For every treatment, four repetitions were performed and the average value was used.

14) The seedlings were grown in field. When male inflowerence appeared, the physical strength of the pseudostem was measured. Stem physical strength apparatus (YYD-IA, Top Apparatus, Beijing, China) was put in the middle of banana seedling pseudostem vertically. Push the apparatus until the angle between the pseudostem and the ground reach to 45 degree. The datum on the screen shown was the pseudostem physical strength measured. For mature banana plant, portable electronic scale was used. The steelyard hook was fixed in the upper pseudostem. The scale was pulled until the angle between the pseudostem and the ground was 45 degree. The datum shown in the screen (D1) was trans- 
formed into the final data (D2) according to the following formula, D2 = D1 $\times$ 9.8. For every treatment, six plants were measured and the average value was used.

\section{Discussion}

We found that banana plants with high physical strength in seedling stage always had high strength at mature stage. The pseudostem physical strength was closely related with pseudostem diameter, lignin content in pseudostem and the expression of Mu4CL. Those seedlings with bigger diameter always had high strength. Similar results had also been found in rice lodging research [4]. Mulder [5] also found that the lodging resistance of plant was mainly determined by the resistance strength of the basic part. The physical strength of plant stem was mainly determined by lignin content in stem [6] [7] [8] [9]. Those plants with high lignin content in stem always had strong resistance to outer pressure [6] [7] [8] [9]. In the process of synthesizing lignin, Mu4CL located at the rate-limiting step [10]. The plants in which Mu4CL was highly expressed always had strong resistance to lodging [11] [12] [13] [14] [15]. We found that in banana, Mu4CL15 was a key gene for synthesizing lignin. Those seedlings in which the expression of Mu4CL15 was more always had higher strength. In one thousand of banana seedlings, five seedlings whose diameter was the most were selected. Five seedlings whose lignin content was the most were selected. Five seedlings in which the expression of Mu4CL15 was the most were selected. The seedlings selected were grown in field. When the seedlings grew to mature stage, the seedlings always had much higher strength than the control. Using this method, the physical strength of pseudostem of banana will be predicted at seedling stage. In seedling stage, thousands of seedlings can be identified in short time. Furthermore, this process does not need large area or much labor. If this method was applied, the process of breeding banana varieties with high resistance to lodging will be shorted significantly.

\section{Acknowledgements}

This work was supported by the Key Research and Developmental Plan Item of Hainan Province (No. ZDYF2017024).

\section{Conflicts of Interest}

The authors declare no conflicts of interest regarding the publication of this paper.

\section{References}

[1] Li, C.Y., Wei, Y.R., Wu, Y.L., Huang, B.Z. and Yi, G.J. (2011) Status, Challenges and S. H. Chang et al. Trends of Chinese Banana Industry. In: Jiang, Z., Yi, G., Molina, A. and Bergh, I., Eds., Proceeding of the International ISHS-ProMusa Symposium Global Perspectives on Asian Challenges, 14-18 September 2001, Guangzhou, 31-36.

[2] Chang, S., Sun, W., Xu, G., Wei, Q., Li, J. and Shu, H. (2017) Enhancing Lodging 
Resistance of Banana Plant by Transforming 4-Coumarate: CoA Ligase Gene Mu4CL15. Molecular Plant Breeding, 15, 1-11.

[3] Gong, J., Dong, B. and Liu Y. (2006) The Standard Process for Planting Banana. South Press, Haikou, 19.

[4] Ishimaru, K., Togawa, E., Ookawa, T., Kashiwagi, T., Madoka, Y. and Hirotsu, N. (2008) New Target for Rice Lodging Resistance and Its Effect in a Typhoon. Planta, 227, 601-609. https://doi.org/10.1007/s00425-007-0642-8

[5] Mulder, E.G. (1954) Effect of Mineral Nutrition on Lodging of Cereals. Plant Soil, 5, 246-306. https://doi.org/10.1007/BF01395900

[6] Ma, Q.H. (2009) The Expression of Caffeic Acid 3-O-Methyltransferase in Two Wheat Genotypes Differing in Lodging Resistance. Journal of Experimental Botany, 60, 2763-2771. https://doi.org/10.1093/jxb/erp132

[7] Jones, L., Ennos, A.R. and Turner, S.R. (2001) Cloning and Characterization of Irregular Xylem4 (irx4): A Severely Lignin-Deficient Mutant of Arabidopsis. Plant Journal, 26, 205-216. https://doi.org/10.1046/j.1365-313x.2001.01021.x

[8] Ma, Q.H., Xu, Y., Lin, Z.B. and He, P. (2002) Cloning of cDNA Encoding COMT from Wheat Which Is Differentially Expressed in Lodging-Sensitive and -Resistant Cultivars. Journal of Experimental Botany, 53, 2281-2282.

https://doi.org/10.1093/jxb/erf102

[9] Halpin, C., Holt, K., Chojecki, J., Oliver, D., Chabbert, B., Monties, B., Edwards, K., Barakats, A.A. and Foxon, G.A. (1998) Brown-Midrib Maize (bm1): A Mutation Affecting the Cinnamyl Alcohol Dehydrogenase Gene. The Plant Journal, 14, 545-553. https://doi.org/10.1046/j.1365-313X.1998.00153.X

[10] Shu, H., Sun, W., Wang, Z., Yin, M., Han, Q., Zhou, Z., Dai, M., Jin, Z., Li, J. and Chang, S. (2016) The Possible Analysis for Breeding Banana Varieties with High Resistance to Typhoon. Molecular Plant Breeding, 14, 1-11.

[11] Saballos, A., Sattler, S.E., Sanchez, E., Foster, T.P., Xin, Z., Kang, C., Pedersen, J.F. and Vermerris, W. (2012) Brown midrib2 (Bmr2) Encodes the Major 4-Coumarate: Coenzyme A Ligase Involved in Lignin Biosynthesis in Sorghum (Sorghum bicolor (L.) Moench). Plant Journal, 70, 818-830. https://doi.org/10.1111/j.1365-313X.2012.04933.x

[12] Wagner, A., Donaldson, L., Kim, H., Phillips, L., Flint, H., Steward, D., Torr, K., Koch, G., Schmitt, U. and Ralph, J. (2009) Suppression of 4-Coumarate-coA Ligase in the Coniferous Gymnosperm Pinusradiate. Plant Physiology, 149, 370-383. https://doi.org/10.1104/pp.108.125765

[13] Gui, J., Shen, J. and Li, L. (2011) Functional Characterization of Evolutionarily Divergent 4-Coumarate: Coenzyme A Ligase in Rice. Plant Physiology, 157, 574-586. https://doi.org/10.1104/pp.111.178301

[14] Lee, D., Meyer, K., Chapple, C. and Douglas, C.J. (1997) Antisense Suppression of 4-Coumarate: Coenzyme A Ligase Activity in Arabidopsis Leads to Altered Lignin Subunit Composition. The Plant Cell, 9, 1985-1998.

https://doi.org/10.1105/tpc.9.11.1985

[15] Hu, W.J., Harding, S.A., Lung, J., Popko, J.L., Ralph, J., Stokke, D.D., Tsai, C.J. and Chiang, V.L. (1999) Repression of Lignin Biosynthesis Promotes Cellulose Accumulation and Growth in Transgenictrees. Nature Biotechnology, 17, 808-812. https://doi.org/10.1038/11758 